\title{
Canadian Neurological Sciences Federation 2017 Congress June 20 - 23 Victoria Conference Centre, Victoria, BC
}

Tuesday, June $20^{\text {th }}, 2017$

8:30 am to $11: 00$ am - Courses

- Hot Topics in Neurology: The Current Future of Neurology

- Hot Topics in Child Neurology

- Hot Topics in Neurosurgery: Recent Advances in Neurosurgery

- Hot Topics in Clinical Neurophysiology: Advances in Neuromuscular Autoimmune Disease

- Neurology Resident Course: Resident Neuroimaging Review, pediatric

$11: 15$ am to $12: 15$ pm - Poster Moderated Sessions

12:15 pm to 1:45 pm - Lunch 'n Learn (unaccredited)

- $\quad$ Alzheimer's and MS

- $\quad$ Spinal muscular atrophy management update. Treatment with anti-sense makes sense.

1:45 pm to 4:15 pm - Resident Courses

- $\quad$ Neurosurgery: Pediatric Neurosurgery

- $\quad$ Neurology: Resident Neuroimaging Review, adult

$1: 45 \mathrm{pm}$ to $4: 15 \mathrm{pm}$ - Courses

- $\quad$ Trends in the Neurosciences

- $\quad$ Competency by Design

4:15 pm to 5:45 pm - Accelerating Diagnosis of Neuromuscular Disorders (unaccredited)

5:45 pm to 7:45 pm - Clinical Case Studies (CCS)

- $\quad$ Epilepsy Video Session

- Neuromuscular

- Movement Disorders

- Headache

- $\quad$ Neurosurgery-Fireside Chat

Wednesday, June $21^{\text {st }}, 2017$

8:00 am to $11: 30$ am - Grand Plenary

- CNS - Richardson Lecture: Sandra Black, 150 Years of Progress in Understanding Alzheimer's Disease: Where we have been, where we are going and what about the future?

- $\quad$ CSCN - Gloor Lecture: Nens van Alfen, What can neuromuscular ultrasound do for you?

- $\quad$ CACN - Tibbles Lecture: Darcy Fehlings, Translational Neuroscience for Hemiplegic Cerebral Palsy: From Cell to Person

- $\quad$ CNSS - Penfield Lecture: John Kestle, Multi-centre research benefits and challenges: a pediatric hydrocephalus example

- $\quad$ Society Prize Winners present during Grand Plenary

11:45 am to 12:45 pm - SPC Chair's Select Abstracts - (Selected as part of Abstract Review Process)

12:45 pm to 2:15 pm - Co-Developed Sessions

- $\quad$ Changing the course of MS: high efficacy therapeutic options

- $\quad$ Recent Advances in CSF analysis in Cognitive Impairment

2:30 pm to 5:00 pm - Multi-disciplinary Courses

- Update in Headache Medicine: Headache and Concussion, Prophylactic Choices in Migraine, The Management of Medication Overuse Headache

- $\quad$ Stroke-Medical and Surgical Aspects

- Movement Disorders

- Brain Tumour Board-Neuro-oncology for Neurologists and Neurosurgeons

- Neuro-ophthalmology

5:00 pm to 7:00 pm - Exhibitors' Reception

7:00 pm to 8:30 pm - Residents' Social

Thursday, June $22^{\text {nd }}, 2017$

8:00 am to 3:45 pm - Society Days (Morning sessions 8am to 10:30am - Afternoon sessions 1:15pm to 3:45pm)

- $\quad$ Child Neurology (CACN) Day

am - Pediatric Movement Disorders

pm - Pediatric Movement Disorders

- $\quad$ Neurophysiology (CSCN) Day

am - Pitfalls in the Interpretation of EEG

pm - EMG in Everyday Practice. (ends at 4:15)

- $\quad$ Neurology (CNS) Day

am - Behavioral Neurology: the Basics and Beyond

pm - Neuropsychiatric Manifestations of Neurological Disease

- $\quad$ Neurosurgery (CNSS) Day

am - Study design in neurosurgery

pm - Neuroradiology/Neurointervention for Neurosurgeons

pm - Difficult Cases in Spine

10:45 am to 11:45 am - Poster Moderated Sessions

11:45 am to $1: 15 \mathrm{pm}$ - Lunch 'n Learn (Unaccredited)

- The long term Implications of selecting an oral disease modifying therapy

$11: 45$ am to $1: 15 \mathrm{pm}$ - Lunch in the Exhibit Hall

4:00 pm to 5:30 pm - MS Duels Program (unaccredited)

6:30pm - CNSF Social Event

Friday, June $23^{\text {rd }}, 2017$

8:30 am to $10: 00$ am - Grand Rounds

10:00 am to $11: 30$ am - Brunch in the Exhibit Hall

11:30 am to 2:00 pm - Multi-Disciplinary Courses

- $\quad$ Exercise in Neurological Illness

- Concussion/Chronic Traumatic Encephalopathy

- Chronic Pain Management for Neuroscience Clinicians 